\title{
Laya Behbahani: Human Trafficking In The Gulf States
}

\author{
Tues, January 31, 2017, 7:00 PM. \\ Djavad Mowafaghian World Art Centre, \\ Goldcorp Centre for the Arts, 149 W. Hastings St.
}

Co-presented by SFU's Vancity Office of Community Engagement, SFU's School for International Studies, the Institute for the Humanities at SFU, and the Global Communication MA Double Degree Program.

Human trafficking in the Gulf Co-operation Council (GCC) states of the Middle East is a growing concern. With over 90 per cent of the population constituting as migrant workers in parts of the Gulf, concerns around the gross human rights violations of migrants workers has attracted the much needed attention it deserves.

Accounts of migrant workers expected to surrender their passports and labour rights upon arrival in the Gulf, signing contracts in languages unbeknownst to them, enduring grave physical, sexual and psychological abuse, and serving as indentured slaves for indefinite periods of time with little or no compensation are not merely sensationalized stories but rather, the lived experiences of a vast number of migrant workers in the GCC.

In this discussion, Laya Behbahani, who recently completed her MA in Criminology at SFU, will provide media accounts of the experiences of migrant workers in the GCC against a backdrop of the hybrid legal system and varying innovative, and often evasive, state responses in the GCC.

Despite the GCC's claim to be operating according to a hybrid legal system whereby Shariah law, common law and civil law are applied to different realms of social transactions, Behbahani argues that the current treatment of migrant works and related policies and practices in the GCC, are not merely labour violations, but are tantamount to state-sponsored human trafficking. She will examine the gap between criminal laws, immigration policies and labour standards, and practices in the GCC that are incongruent with international norms and standards with respect to the treatment of migrant workers.

Behbahani will examine how human trafficking in the GCC is strikingly similar to, or at minimum entails forms of modern day slavery. Understanding the proximity of slavery to human trafficking provides a basis for arguing that human trafficking and slavery are not distinct enough crimes so as to prevent human trafficking from being exclusively catalogued as a jus cogens norm in international law.

A post-lecture dialogue will be moderated by SFU School of Communication's Adel Iskandar.

\section{Speaker Bios}

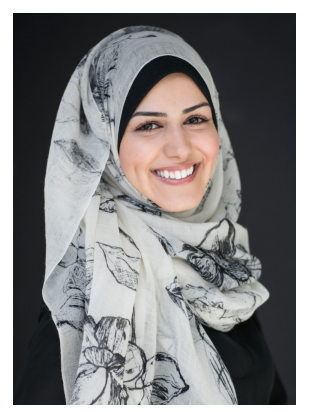

Laya Behbahani is a Business and Policy Analyst at Simon Fraser University. She is also a sessional lecturer in Labour Studies and an associate at the Police Studies Centre at the School of Criminology at SFU. 
She has previously worked at the Human Trafficking and Migrant Smuggling Section of the United Nations Office on Drugs and Crime in Vienna, Austria, the Just Governance for Human Security conference in Geneva, Switzerland and as a research associate at the Centre of Excellence in Responsible Business at York University's Schulich School of Business.

Behbahani completed her BA with Honours and Master's at the School of Criminology at SFU before completing further course work at the University of Vienna, BCIT and Harvard University's Kennedy School of Government. Her research focuses on international trade, labour and human trafficking in the global political economy.

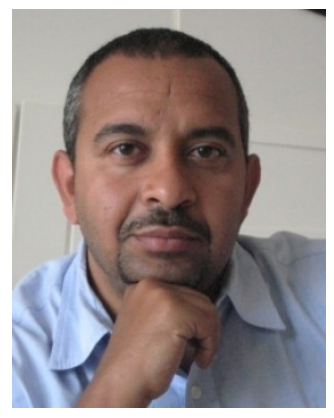

Adel Iskandar is an Assistant Professor of Global Communication at Simon Fraser University. He is the author, co-author, and editor of several works including Egypt In Flux: Essays on an Unfinished Revolution (AUCP/OUP); AlJazeera: The Story of the Network that is Rattling Governments and Redefining Modern Journalism (Basic Books); Edward Said: A Legacy of Emancipation and Representation (University of California Press); Mediating the Arab Uprisings (Tadween Publishing), and Media Evolution on the Eve of the Arab Spring (Palgrave Macmillan).

Iskandar's work deals with media, identity and politics; and he has lectured extensively on these topics at universities in more than thirty countries. His forthcoming works deal with propaganda and cultural dissidence online. Prior to his arrival at SFU, Iskandar taught for several years at the Center for Contemporary Arab Studies and the Communication, Culture, and Technology Program at Georgetown University, in Washington, DC. He is a co-editor of the online publication Jadaliyya. 